\title{
Narrative Deliberation? On Storytelling as a Necessary Component of Public Deliberation
}

\author{
Marcos ENGELKEN-JoRGE \\ Humboldt Universität zu Berlin \\ marcos.engelken-jorge@hu-berlin.de
}

Recibido: 25-02-2015

Aceptado: 15-02-2016

\begin{abstract}
This paper deals with the place of narrative, that is, storytelling, in public deliberation. A distinction is made between weak and strong conceptions of narrative. According to the weak one, storytelling is but one rhetorical device among others with which social actors produce and convey meaning. In contrast, the strong conception holds that narrative is necessary to communicate, and argue, about topics such as the human experience of time, collective identities and the moral and ethical validity of values. The upshot of this idea is that storytelling should be a necessary component of any ideal of public deliberation. Contrary to recent work by deliberative theorists, who tend to adopt the weak conception of narrative, the author argues for embracing the strong one. The main contention of this article is that stories not only have a legitimate place in deliberation, but are even necessary to formulate certain arguments in the first place; for instance, arguments drawing on historical experience. This claim, namely that narrative is constitutive of certain arguments, in the sense that, without it, said reasons cannot be articulated, is illustrated by deliberative theory's own narrative underpinnings. Finally, certain possible objections against the strong conception of narrative are dispelled.
\end{abstract}

Key words: deliberative democracy; narrative; discourse; rhetoric.

\section{¿Deliberación narrativa? Acerca de la necesidad de contar historias en la deliberación pública}

\section{Resumen}

Este artículo aborda el papel de las narraciones en la deliberación pública. Se diferenciará entre una concepción débil y otra fuerte de las mismas. La primera ve el contar historias como un recurso retórico entre otros muchos con el que los actores sociales crean sentido y se comunican, mientras que la segunda concibe las narraciones como necesarias para la comunicación y el debate sobre temas tales como la experiencia del tiempo, las identidades colectivas o la validez moral y ética de los valores. El corolario de esta idea es que las narraciones deben ser elementos esenciales de todo ideal de deliberación. En contra de las posturas recientes de un buen número de teóricos deliberativos, quienes tienden a adoptar una concepción débil de las narraciones, se argumentará la idoneidad de asumir una concepción fuerte de las mismas. La principal tesis de este trabajo es, por tanto, que las narraciones no solo tienen un papel legítimo en la deliberación, sino que resultan indispensables para formular determinados argumentos en primera instancia; por ejemplo, aquéllos que beben de la experiencia histórica. La idea de que las historias son constitutivas de determinados argumentos, en el sentido de que sin las mismas éstos no podrían ser formulados, se ilustrará poniendo de relieve el propio sustrato narrativo de la teoría deliberativa. Finalmente, se despejarán ciertas posibles objeciones a la concepción fuerte de las narraciones.

Palabras clave: democracia deliberativa; narración; discurso; retórica.

\section{Referencia normalizada}

Engelken-Jorge, M. (2016): "Narrative Deliberation? On Storytelling as a Necessary Component of Public Deliberation”, Política y Sociedad, 53 (1), pp. 79-99. 
Contents: Introduction. 1. The Epistemic Justification of Deliberative Democracy. 2. The Weak Conception of Narrative. 3. The Strong Conception of Narrative. 4. Arguments against Deliberative Democracy Derived from the Strong Conception of Narrative. 5. Meeting Some Objections. 6. Meeting the Objection of Ethnocentrism: The Narrative Justification of Deliberative Democracy. 7. Conclusion and Future Research. 8. References.

\section{Acknowledgement}

The author would like to express his gratitude to two anonymous reviewers for their comments and suggestions. This paper is part of the LearningDemoi project, supported by a Marie Curie Intra-European Fellowship within the $7^{\text {th }}$ European Community Framework Programme.

\section{Introduction}

Deliberative democracy gained currency in the 1980s and 1990s as a normative theory intended to consolidate existing liberal democracies. Since then, it has not only attracted much academic debate, but also inspired political reforms and experimentation with different institutional innovations. In this regard, Chambers noted already in 2003 that deliberative democratic theory had "moved beyond the 'theoretical statement' and into the "working theory' stage" (Chambers, 2003: 307). This notwithstanding, the concept of deliberation has remained a matter of debate.

Bächtiger et al. (2010) have tried to introduce some order into this debate by distinguishing between two concepts of deliberation, which they simply label "type I" and "type II." According to this distinction, type I conceptions regard deliberation as "a systematic process wherein actors tell the truth, justify their propositions extensively, and are willing to yield to the force of the better argument" (Bächtiger et al, 2010: 33). This concept of deliberation has attracted much criticism, however. Among other things, it has been criticised for undermining political equality, on the basis that it privileges certain social groups -typically citizens with higher levels of educationwho are better at articulating abstract arguments and framing them in terms of the hegemonic conception of the common good than other groups, which furthermore, are usually already underrepresented politically (Sanders, 1997; Young, 2001). Besides, such a concept of deliberation has been considered too rationalistic and thin to be motivationally efficacious, as it tends to exclude emotional talk, storytelling and other forms of communication capable of arousing emotions and processes of identification and empathy (Abizadeh, 2007). Interestingly, these and further criticisms ${ }^{1}$ have contributed not so much to abandoning deliberative theory altogether, but to its revision along the lines of type II deliberation, as well as to making this type II conception more popular among political scientists.

${ }^{1}$ In this regard, see Bächtiger et al. (2010) and Yack (2006). For more extensive discussions, see Fontana et al. (2004) and Steiner (2012). 
Quoting Warren (2007), type II deliberation is defined by Bächtiger et al. (2010: 33) as "all activities that function as communicative influence under conditions of conflict." As such, deliberation involves not only the giving and taking of arguments, but also other forms of communication, such as storytelling, the giving of testimony, the use of humour, sarcasm, emotional communication, and so on. At its limits, one can go as far as to claim, with Young (2010: 688), that demonstrations, cartoons, musical works, and so forth, also function as communicative influences under conditions of conflict and thus should be regarded as contributing to public deliberation. A number of authors have embraced one version or another of type II deliberation, from Habermas (1992) and Dryzek (2010) to Chambers (2009) and Parkinson and Mansbridge (2013), or Ibarra Güell (2011), among others. These different approaches -as stressed by Bächtiger et al. (2010: 42) - do not constitute a "fully coherent program," but they do at least form "a distinguishable approach in deliberative theory."

However, there are some aspects of type II deliberation that are still under-theorised and in need of further elaboration. This is the case of the recognition of storytelling as a legitimate practice within public deliberation. Although previous studies have addressed this topic explicitly (e.g. Boswell, 2013; Polletta and Lee, 2006; Young, 2002), there are still further issues that need to be clarified. In particular, there are at least two understandings of the concept of narrative: a weak one, which is clearly compatible with deliberative theory, and a strong one, which has been interpreted, as by Rorty (1989), as challenging some of the basic tenets of deliberative democracy. So, it is far from clear whether storytelling and narrative forms of communication can consistently be integrated into the concept of deliberation or whether this is a move that will eventually undermine the whole theoretical edifice of deliberative theory.

In this article I will pursue this question. Drawing on a broader range of authors than those usually considered by deliberative democrats, I distinguish between weak and strong conceptions of narrative, and use this distinction to make sense of the main theoretical positions in the debate about narrative's place in deliberation. According to the weak conception, storytelling is but one rhetorical device among others with which social actors produce and convey meaning. In contrast, the strong understanding of narrative holds that storytelling is unavoidable when it comes to, for example, expressing the human experience of time or defending the moral or ethical validity of values. The upshot of this idea is that narrative should be a necessary component of any ideal of public deliberation. Contrary to recent work by deliberative theorists, who tend to adopt, explicitly or implicitly, the weak conception of narrative, I argue for embracing the strong one. In my view, storytelling not only has a legitimate place in deliberation, but it is also necessary to formulate certain arguments in the first place; for example, arguments drawing on historical experience. This, I believe, can be illustrated by deliberative theory's own narrative underpinnings. Besides, to strengthen my case for the strong conception of narrative, I discuss Rorty's interpretation of this strong concept of storytelling and dispel some objections against deliberative theory that can be drawn from it.

The argument unfolds in seven sections. In the first one, I briefly introduce the epistemic justification of deliberative democracy, for the arguments put forward by 
these epistemic accounts are precisely what is at stake in debates about narrative and deliberation. In the second section the weak notion of narrative is presented, which is the form that has usually been contemplated by deliberative theorists. It is argued that it is compatible with deliberative democracy, at least from a theoretical perspective. With regard to the stronger conception, presented in the third section, it has been used to undermine arguments for the epistemic dimension of deliberative democracy, thus challenging central ideas of deliberative theory. These arguments are spelled out in section four, although in the next section I shall contend that this specific interpretation rests on shaky logical and conceptual grounds. Furthermore, this discussion will help to highlight the narrative underpinnings of deliberative theory itself, which are reconstructed in section six. This, I conclude, should make plausible the claim that narratives are not only compatible with deliberative democracy and its epistemic justification, but also that they are necessary in public deliberation, for without narrative elements certain arguments cannot be articulated in the first place. ${ }^{2}$

\section{The Epistemic Justification of Deliberative Democracy}

For a number of deliberative theorists (e.g. Estlund, 2009; Habermas, 2006; Lafont, 2006; Martí, 2006), deliberative democracy can be justified in epistemic terms, and some of them even go as far as to argue that this epistemic conception "becomes unavoidable for deliberative democrats" altogether (Martí, 2006: 28; emphasis added). While the exact contours of this epistemic conception differ depending on the author, the main idea, common to most of them, is that any consistent defence of deliberative democracy has to account among other things for why democracy ought to be deliberative (Lafont, 2006). It should be so, according to this argument, because deliberation is a decisionmaking procedure which is more likely to yield "substantively correct outcomes (i.e., just, efficient, good, etc.)" (Lafont, 2006: 7) than other democratic decision-making procedures. In more limited terms, others argue that there are good reasons to believe that deliberation is at least more likely to produce "robust" decisions by reducing "error" (Bohman, 2007).

The reasons for these beliefs are varied. Public deliberation is thought to fulfil a number of functions: to encourage the expression of all relevant interests, concerns and preferences on a specific topic, as well as the intensity with which these preferences are held; to increase the pool of available information; to make political manipulation more difficult; to promote the critical examination of arguments and of their premises; to clarify the exact content of a political controversy and its different dimensions; to order transitively the political preferences of the participants. In sum, public deliberation

${ }^{2}$ One further caveat might be necessary. When scholars speak of storytelling, they often refer, though usually implicitly, to personal stories. The fact that storytelling is sometimes discussed in conjunction with testimony attests to this. However, it is also true that discussions of the relation between narrative and deliberation normally pretend to range wider, including not only personal narrative, but also "political narrative" more generally (Young, 2002: 72). This paper concentrates on this broader understanding of storytelling. 
is said to "mobilize relevant topics and claims, promote the critical evaluation of contributions, and lead to rationally motivated yes or no reactions" (Habermas, 2006: 413), which in turn grounds "[t]he presumption of reasonable outcomes".

Empirical research has produced significant evidence to support the tenet that deliberation has an epistemic edge. In this regard, at least three mechanisms operate within public deliberation giving it an epistemic dimension (Engelken-Jorge, 2014: 8688). First, participants are forced by deliberation to attend to the interests, values and opinions put forward by other interlocutors, in this way encouraging the formulation of shared interests and shared perspectives. Second, deliberation favours the critical scrutiny and assessment of the arguments and statements voiced by the participants in a deliberative process, which contributes to eliminating ambiguities, vagueness and fallacies from public debate. Third, by encouraging mutual communication, deliberation promotes the sharing of factual information. Deliberation, then, contributes to the development of political preferences that tend to accommodate the interests and values of other citizens, are more likely to be based on collectively accepted arguments and forms of reasoning, and tend to rest on a greater pool of factual information. These three aspects are supposed to grant deliberation an epistemic edge over other democratic decision-making procedures, which in turn grounds the claim that democracy should be deliberative.

As we shall see in the next sections, there are two meanings of narrative in the scholarly literature: one of them can easily be reconciled with this epistemic edge of deliberation; the other one, however, has been interpreted as posing a greater challenge. ${ }^{3}$

\section{The Weak Conception of Narrative}

Essentially, the main difference between weak and strong conceptions of narrative lies in the theoretical work that one wants the concept of narrative to do. In both cases, however, a narrative or story can be defined, rather conventionally, as "a description, either true or imagined, of a connected series of events." ${ }^{4}$ In more sophisticated terms, we might define narratives as "constellations of relationships (connected parts) embedded in time and space, constituted by causal emplotment" (Somers, 1994: 616). Stories, then, are a specific form of arranging and conveying information, as well as producing meaning, which is principally characterised by connecting different events together and turning them into episodes of a broader interrelated sequence of events. As

${ }^{3}$ Many of the arguments made in the following two sections are also advanced in the recent literature on political rhetoric (Garsten, 2011). Here, however, I will draw on work in social theory, which I favour essentially because in this sociological literature the difference between weak and strong conceptions of narrative, which I deem crucial to make sense of current debates on deliberation and storytelling, becomes more evident.

4 This definition of the term story has been taken from the Cambridge Online Dictionary, consulted $25^{\text {th }}$ August 2014. Narrative, for its part, is defined as "a story or a description of a series of events" - hence, both concepts can be taken as synonyms. 
such, narratives might range from personal stories and everyday anecdotes to historical accounts of long-term macro processes.

The weak conception of narrative simply takes stories as one rhetorical device among others through which actors can produce and convey meaning. This is a rather common way of seeing storytelling. ${ }^{5}$ The way the debate about narrative's place in deliberation is usually framed, for example, already suggests a weak conception of narrative. The central question of this debate, namely, whether or not storytelling should be granted a place in deliberation (cf. Bächtiger et al., 2010: 55-56; Dryzeck, 2000: 48; Neblo, 2007: 533-534; Steiner, 2012: 57-87), already implies that it would make sense to conceive of deliberation as devoid of narrative elements -an idea that the strong conception of narrative would certainly reject. Even the article that comes closer to the strong conception of narrative in the last years, the one by Boswell (2013), fails to make the full transition from the weak to the strong concept of storytelling. This author rightly pinpoints the value of narrative and goes as far as to argue that storytelling is a "crucial mechanism by which people actually make sense of and communicate about political issues" (Boswell, 2013: 623). Therefore, he argues, it should be taken into account when envisaging and studying deliberative systems at a macro scale. Thus he fails to take the final step and acknowledge, as the strong conception of narrative would have it, that narrative is actually unavoidable when it comes to communication about issues such as values, identities and the experience of time, both in deliberative systems and face-to-face interactions.

Be that as it may, this weak conception of storytelling can easily be integrated into a deliberative framework. For one thing, narratives can be regarded as a particularly efficient device with which to disseminate certain claims and ideas. For whatever reason, it seems that narratives resonate better with the way most people communicate, imagine and explain the world than abstract forms of reasoning (Tilly, 2002). Narratives, in this regard, contribute to disseminating ideas and information in an accessible form. Thus, they might facilitate the integration of individuals less capable of arguing in abstract terms into a deliberative system (Sanders, 1997; Young, 2001). Furthermore, they have the potential to make systems of distributed deliberation more cohesive, as stories travel easily across deliberative sites and facilitate communication between people with different degrees of expertise and knowledge (Boswell, 2013). Moreover, storytelling might help to build trust, promote mutual recognition and establish credibility; it might also favour less agonistic forms of interaction (Polletta and Lee, 2006; Steiner, 2012: 57-64).

Certainly, there are also shortcomings associated with narratives. Their frequent ambiguity and openness to interpretation can be seen as undermining conceptual clarity and rigour, which are precisely two key elements of the epistemic dimension

${ }^{5}$ Ironically, one of the first treatments of the place of narrative in deliberation comes closer to the strong conception of storytelling than to the weak one. I am referring to Young (2002; see in particular p. 75). Given that Young (2002: 71) herself acknowledged her debt to other scholars in her treatment of narrative, I will not concentrate on her work in this paper. Rather, I will pay attention to the sociological literature (see also footnote 3 ). 
of deliberation (Niemeyer, 2011). The point, however, is that storytelling, in this weak sense, does not preclude its critical examination; that is, in public deliberation, narratives can be criticised for being too ambiguous, for disregarding crucial facts, manipulating information or establishing misleading connections between events. This is very much the same as with arguments, which can be fallacious, illogical, based on wrong or partial information, and so on. This is not a problem as long as deliberation exhibits a self-correcting dynamic.

The point, then, is that narratives understood in the weak sense are not conceptually incompatible with deliberative democracy. In fact, they might be instrumental in disseminating certain ideas and achieving some ends which are beneficial to public deliberation. Frequently, however, storytelling might also undermine deliberation. Sorting out when this is the case is, however, an empirical question -it is much more related to how people use stories than to the concept of story itself. On a theoretical level, then, one can only conclude that narratives, in this weak sense, can have a place in deliberative theory without this being inconsistent with the theoretical framework of deliberative democracy.

\section{The Strong Conception of Narrative}

As affirmed earlier, weak and strong conceptions define narrative in similar terms. Their main difference lies not so much in how they distinguish narratives from other rhetorical forms, but in the theoretical significance they attribute to them. The starting idea of this strong conception is rather widespread. It argues that culture is essentially shaped by shared narratives. Alexander (2004: 568) encapsulates this tenet when he states that "[c]ulture is less toolkit than storybook". This idea of culture as storybook is related to what Somers (1994: 613-614) calls "ontological narrativity": "social life is itself storied ... people are guided to act in certain ways, and not others, on the basis of the projections, expectations, and memories derived from a multiplicity but ultimately limited repertoire of available social, public, and cultural narratives." Similarly, Fisher (1984), drawing on MacIntyre, elevates storytelling to a human communication paradigm, according to which "humans are essentially storytellers,", and "the world is a set of stories" (Fisher, 1984: 7-8). ${ }^{6}$

Notwithstanding expressions such as "ontological narrativity," this conception of stories is essentially an empirical notion through which social scientists try to characterise the symbolic world in which social actors live. Thus, according to this account, it is ultimately an empirical fact that the social world is structured by shared

${ }^{6}$ The fact that the strong conception of narrative is "widespread," as I said, does not mean that there is a single and agreed upon notion of culture. Indeed, culture has been variously conceived of as toolkit (Swidler, 1986), webs of significance (Geertz, 1973), storybook (Alexander, 2004) or as composed of schemes, among other things (for an overview of the plurality of ways in which culture can be conceptualized, see Wuthnow, 1992). Since the point here is not to define what culture really is, but to introduce the strong conception of narrative, I will leave open the issue of how these different notions of culture relate to the strong image of narrative. 
narratives. What it says is, essentially, that research systematically shows that stories play a key role in a number of social phenomena, so we have good reasons to generalise this conclusion and say things like "social life is itself storied" (Somers, 1994: 613614) or "humans are essentially storytellers" (Fisher, 1984: 7).

However, scholars have sought to go beyond empirical observation, trying to account for the pervasiveness of narrative. ${ }^{7}$ The work of Ricoeur has been highly influential, as it points to what is probably narrative's most distinctive feature, namely its capacity to grasp the experience of time. For this philosopher, the very structure of stories, that is, their emplotment, combines a chronological dimension as well as a "configurational dimension," which turns isolated events into ordered, interconnected episodes, in this way creating "significant wholes" (Ricoeur, 1979: 24). As such, narrative brings "the mode of being which we call temporality ... to language" (Ricoeur, 1979: 17). Similarly, Somers (1998: 767) contends that "the world is made up of things that are constituted through temporal and spatial relationships and thus must be represented in relational and narrative terms" (her emphasis). Certainly, other scholars have argued that other methodological concepts, such as general laws or causal mechanisms, ${ }^{8}$ also serve to represent, and make sense of, history, that is, the human experience of time. The point is, however, that a number of historical processes and events only happen once or very rarely and thus are not amenable to being elucidated and communicated through non-narrative forms of rhetoric. In short, according to the strong conception of narrative, the symbolic processing of history requires storytelling.

Other scholars have pointed out additional features of narrative, although they can be considered of secondary importance in this context. This is not because they are irrelevant tout court, but because there are other rhetorical forms of expression that can do the same job. For example, stories are said to arouse emotions and especially feelings of identification in a way that abstract reasoning cannot (Fisher, 1984: 9) -but it is also true that emotions can also be aroused by, say, poetry or the (non-narrative) description of an injustice. Hence, one cannot claim that storytelling is indispensable in public deliberation because of its emotion-arousing ability. Having said this, I am willing to concede that narrative's ability to arouse emotions enhances the importance of storytelling for public deliberation. For instance, scholars usually highlight a third feature of narrative, namely its performative dimension, which relies upon narrative's capacity to express the experience of time and to stir emotions, in particular feelings of identification. By telling stories, people not only communicate, but also sometimes create things. For example, they create collective identities by recounting (or inventing) past events and allegedly shared traditions that justify group boundaries, with which

7 This, admittedly, has created some ambiguity, as it makes the strong conception of narrative fluctuate between relying on empirical observation on the one hand and speculative arguments on the other one. This notwithstanding, I believe that the point made in the previous paragraph still holds, namely the strong conception of narrative rests mainly on empirical observation rather than other kinds of arguments.

${ }^{8}$ Although it is highly debatable whether causal mechanisms can do the job they are intended to do in the absence of narrative elements (Somers, 1998: 768-772). 
people can identify (Eder, 2006, 2007). By narrating their past, people provide their lives with a sense of continuity, thus giving rise to personal identities (Ricoeur, 1990). Social actors also produce understandings of past events by telling stories about them, which are then used to justify values (Joas, 2008: 91; 2011) and "moral universals" (Alexander, 2002). In all these cases, it is argued that by giving them narrative plausibility and motivating people to identify with them, stories create these social and symbolic phenomena.

Thus the strong conception of narrative claims that there is no functional equivalent to storytelling when it comes to communication on topics such as the experience of time, values or identities, in the sense that with alternative forms of communication there would be a loss of meaning. This is a powerful observation. Essentially, it says that the debate between proponents of type I and type II deliberation, at least regarding whether storytelling should be accepted as part of deliberation, is ill-posed. Empirically, it is hard to imagine a public sphere devoid of narrative elements. From a normative perspective, it is doubtful that an ideal of deliberation that excluded narrative would be desirable, for it would not only rule out a specific form of communication, but by doing so, it would also exclude certain arguments and ideas that can only be grasped in narrative form. For example, it would exclude recourse to specific historical events or processes that can be recalled in order to strengthen an argument or even in order to make an argument. Precisely deliberative theory provides an example of the latter case, which is presented below.

This strong conception of narrative is not necessarily incompatible with deliberative theory. Indeed, in the next sections of this paper I will embrace this conception and still argue for deliberative democracy as a prima facie valid and coherent political ideal. As suggested earlier, as long as storytelling does not erode the self-correcting dynamic of public deliberation, that is, as long as narratives can be criticised and revised for not getting the facts straight, being inconsistent or implausible, and so forth, the arguments for the epistemic dimension of deliberative democracy still hold. However, as interpreted by other authors, this strong idea of narrative undermines the epistemic argument for deliberative democracy. I will now turn to this interpretation. ${ }^{9}$

${ }^{9}$ Apart from the ones that will be presented below, there are further objections against deliberative democracy that are linked to the concept of narrative. For instance, feminists have stressed storytelling's contribution to the "facilitation of local publics and [the] articulation of collective affinities." This is -they claim-a matter downplayed by deliberative democrats, which cannot be adequately addressed by a concept of deliberation narrowly conceived (Young, 2002: 73). However, unlike the objections presented in the next section, this and similar criticisms are not so much aimed at undermining the theoretical foundations of deliberative democracy, but seek instead to broaden deliberative democracy's ideal of public communication. For this reason, as well as due to space limitations, I will not consider these further objections in this paper. 


\section{Arguments against Deliberative Democracy Derived from the Strong Conception of Narrative}

Famously, one author interpreting the strong conception of narrative in such a way as to undermine deliberative theory is Richard Rorty. Although Rorty (1989) does not so much speak of narratives or stories but of processes of "redescription," narratives figure prominently in his account, especially in the form of novels and other literary texts. They contribute to instituting "final vocabularies" which mediate our relation with the world, including ourselves and other persons as well as social groups. If the strong conception of narrative stresses the performative dimension of stories, in the sense that they are seen as contributing to creating things like personal and collective identities, one can say that Rorty goes a step further and argues that stories contribute to creating cognitive systems or final vocabularies. More recently, Finlayson (2012) has also stressed the poetic and performative capacity of language. One of his central arguments is that public controversies often centre not so much on arguments and the conclusions that follow from shared premises, but on the premises themselves. "What is at issue is the nature of the event or phenomenon [around which public controversies revolve], which is produced in its description and through the narrative context in which it is placed" (Finlayson, 2012: 762). To analyse these public disputes, one should focus, among other things, on the "range of 'quasi-logical' forms of argument" used, i.e. "attempts to produce in audiences conclusions taken to follow naturally from certain premises" (Finlayson, 2012: 761), as well as on the creative and "evangelic" character of communication, which shows and invents rather than "demonstrates" (Finlayson, 2012: 762-763). What is implicit in Finlayson's selection of words is made explicit by Rorty. In this regard, I would like to highlight three ideas.

First, for Rorty, as well as for others (e.g. Martin, 2002), beliefs hang together by webs of implications forming cognitive systems that vary historically and culturally. The crucial point is that these webs of implications do not reflect any intrinsic properties of beliefs, but are created and maintained by other means: a linguistic community, epistemic authorities, shared narratives, etc. This has implications for standards of rationality, which are seen as dependent upon these cognitive systems. For example, although nowadays it would seem utter nonsense, "[i]n the sixteenth century it was only rational to test astrophysical or biological theories against holy scripture" (Rorty, 2007: 925; cf. Martin, 2002: 870-873).

Second, the fact that standards of rationality are context-specific is taken to mean, from a logical perspective, that the scope of argumentation is very limited. That is, most of the time, what we find in public controversies are not instances of argumentation but of redescription:

"The method is to redescribe lots and lots of things in new ways, until you have created a pattern of linguistic behavior ... It does not pretend to have a better candidate for doing the same old things which we did when we spoke in the old way. Rather, it suggests that we might want to stop doing those things and do something else. But it does not argue for this suggestion on the basis of antecedent criteria common to the old and the new language games. For just insofar as the new language really is new, there will be no such criteria." (Rorty, 1989: 9) 
For similar reasons, contextualists also tend to think of ethical and moral standards as culture-dependent. Again, Rorty provides a passage which is worth quoting at length:

"Once, for example, it would have sounded crazy to describe homosexual sodomy as a touching expression of devotion, or to describe a woman manipulating the elements of the Eucharist as a figuration of the relation of the Virgin to her Son. But such descriptions are now acquiring popularity. At most times, it sounds crazy to describe the degradation and extirpation of helpless minorities as a purification of the moral and spiritual life of Europe. But at certain periods and places-under the Inquisition, during the Wars of Religion, under the Nazis-it did not." (Rorty, 1990a: 6)

From these ideas, a number of interconnected challenges follow for deliberative theory. I will simply mention them briefly:

First, one can argue that many social conflicts cannot be resolved by "rational" means. In the last instance, they are but clashes of final vocabularies which are incommensurable, there being no neutral ground to adjudicate between them - only further final vocabularies which are equally incommensurable. If, for example, human rights rest upon a previous process of "sacralisation" of the person (Joas, 2011), then there is no meaningful way of arguing for them unless our interlocutors share this same belief in the sacredness of individuals, that is, this same final vocabulary, which creates in the first instance the logical space where human rights arguments can find resonance.

Second, in these cases, public arguments consist of instances of redescription, which are different from rational argumentation, as stated earlier.

Third, it can be argued that the epistemic justification of deliberative democracy is ethnocentric. Actually, given the strong contextualist arguments introduced earlier, any political ideal would probably be ethnocentric. In the case of deliberative democracy, it is unconvincing because it is based upon egalitarian and universalistic values which are not shared by everybody, but are rather grounded in culture-specific narratives. Thus, integrating the (strong) conception of narratives into the theoretical edifice of deliberative democracy would be akin to a Trojan horse; namely, it would severely undermine or restrict the epistemic account of deliberative democracy, which, as argued earlier, is seen by many deliberative democrats as crucial for any justification of deliberative democracy in the first place. Deliberative theorists would be forced to choose between giving up any epistemic justification of deliberative democracy which would compel them to find new ways of justifying this ideal or to abandon it altogether- and on the other hand, restricting to specific cultural contexts the claim that deliberative democracy has an epistemic edge -namely to those contexts in which the specific interpretation of the liberal and egalitarian values upon which deliberative democracy is based is already widespread. For only people already sharing these values and the narratives upon which they are based could construe the outcomes of deliberative processes as epistemically superior, since only those people could see moral value in including all those affected by a political decision, in treating them as well as their interests equally, in allowing them to speak for themselves and showing respect for their moral autonomy, and so forth. 
In the next section, I shall recall the shortcomings of the first two challenges, which have already been discussed at length elsewhere. To be sure, the third challenge has also already been tackled in the specialised literature. However, I will devote more attention to it to show that deliberative democratic theory itself has a historically specific narrative grounding.

\section{Meeting Some Objections}

The aforementioned criticisms rest on shaky logical and conceptual grounds. Although from an epistemological perspective any strong contextualist position seems to be selfdefeating (Hatcher, 1994), it can be conceded that when it comes to practical questions, which involve ethical and moral considerations, these arguments gain more plausibility. However, even in this latter case, they have been criticised for several reasons. To begin with, the claim that final vocabularies are incommensurable seems to be implausible. "[T]he problem," as stated by Bailin (2003: 7-8), "is that comprehension seems to presuppose continuity. If a new idea or practice emerged which were totally unconnected with any human traditions and practices, we would not be able to understand it." Certainly, there might be cases of local incommensurability, that is, between competing values or between subsets of terms or language games (Oberheim, 2003), but it is hard to believe that two sets of final vocabularies are completely incommensurable, as this would impede any communication and understanding between them in the first place.

A second criticism is related to contextualists' misconception of argument. According to them, argument is opposed to redescription, which is creative and in a sense performative. Arguments should demonstrate rather than show or reveal (Finlayson, 2012: 762), and they should be conclusive, amounting to a "knockdown answer" to a counter position (Rorty, 1990b: 636). They are, in sum, "algorithmic", that is, they operate according to the rules and within the limits of a given final vocabulary (Bailin, 2003: 12). The problem with this view, however, is that it is inappropriate to describe real arguments in everyday settings (Bailin, 2003: 12). First, arguments are creative -for instance, finding counter examples and formulating new reasons for or against something entails some creativity. Second, they are usually non-deductive. In natural language, argumentation normally rests on ampliative arguments, that is, arguments the conclusions of which go beyond the premises and are therefore more or less probable or plausible, lacking deductive certainty (Bohman y Rehg, 2014). As understood by deliberative democrats and informal logicians, arguments simply provide reasons for or against something, without these reasons being definitive or purely deductive. As such, the strict opposition between redescription and argumentation collapses. According to this account, then, showing how alternative forms of viewing things is more consistent with the available evidence or with someone's values or beliefs -or showing how this alternative way of looking at things can realise or promote someone's values to a greater extent- is not necessarily a mere instance of redescription, but can be considered an argument according to the way most deliberative democrats and informal logicians understand this concept. Certainly, sometimes redescription is just redescription, as when people talk past each other, framing and reframing a question without really 
engaging the interlocutor. At other times, however, redescription can function as an argument -it says something along the lines of: 'Look, with this way of looking at things you have these inconsistencies; but if you look from this perspective, these problems disappear.' Indeed, this is one of the main arguments used by authors such as Luhmann (1984) or MacIntyre (1984) in support of their respective theories.

Still, this does not solve the problem of value incommensurability. Two political positions might conflict because they happen to support two apparently incommensurable values - i.e. values which have been "founded" on different sets of narratives that confer on them plausibility. The value of individual liberty, for example, might be brandished to defend the right to euthanasia, while opponents might wield the inviolability of human life. From a logical perspective, neither the fact that final vocabularies must overlap if communication is to be possible at all nor the revised concept of argument in line with its common function in everyday language use seem to eliminate these cases of value incommensurability.

Certainly, conflicts of this kind reveal the limits of deliberation. The point, however, is that although one can concede that certain conflicts cannot be resolved by the give and take of argument (or can hardly be resolved in this way), once the concept of incommensurability has been reduced to local incommensurability and the opposition between redescription and argumentation (as conceived by authors such as Rorty) has been discredited, value incommensurability no longer represents a purported sphere of human action which is void of communicative rationality, that is, which can be reduced to a mere clash of final vocabularies. Deliberation can contribute to clarifying the exact points of controversy (Miller, 2006: 129-156) and it can provide insight into why people disagree and hold the values that they happen to hold, thereby contributing to the decentring of one's own perspective and to promoting forms of legitimate dissent, that is, dissent based on reasons which both parties understand and find reasonable although they weigh them differently (Dryzek and Neimeyer, 2006; ${ }^{10}$ Kock, 2007). In other words, value incommensurability is not the same as, nor does it presuppose, (full, i.e. non-local) logical incommensurability.

\section{Meeting the Objection of Ethnocentrism: The Narrative Justification of Deliberative Democracy}

I considered the aforementioned objections not only because the strong conception of narrative can be interpreted, as by Rorty and Finlayson, as challenging deliberative theory, but also because it provides insight into one aspect of the relation between deliberative democracy and storytelling that has largely been ignored thus far; namely, what can be called the narrative justification of deliberative democracy.

In line with the strong conception of narrative, my contention is that it is meaningless to debate whether storytelling should be part of deliberation, since there is no functional

${ }^{10}$ To be sure, Dryzek and Niemeyer (2006) do not speak of legitimate dissent but of "metaconsensus." The latter, however, can be regarded as the other side of the coin of legitimate dissent (in this regard, see Kock, 2007). 
equivalent to narrative when it comes to communication about issues such as identities, values and the experience of time. To give some plausibility to this claim, I shall show that deliberative democracy itself has to rely on certain narratives to be defended as a political ideal.

Earlier, a question was raised which I have not answered thus far, namely whether deliberative democracy is an ethnocentric ideal. The scholarly response to this challenge has consisted in embedding deliberative democracy in, first, a broader account of what constitutes intellectual and moral progress and second, in a historical (though stylised) narrative about cultural pluralism and its concomitant political challenges. The latter narrative has been provided by Habermas, while the former account of intellectual and moral progress has been developed by pragmatist philosophers (and Habermas himself), partly based on Kuhn's account of scientific progress. In line with my argument thus far, this historical and narrative justification of deliberative democracy does not provide a definitive argument for this political ideal, but simply good reasons (although ultimately fallible ones) for embracing it.

Famously, Kuhn's account of scientific progress is an evolutionary one in the sense that it regards scientific development as moving away from the anomalies and dysfunctions of dominant theories, rather than moving towards some fixed goal (cf. Oberheim, 2013). Repeated failures to predict the occurrence of certain events, the inability of a theory to explain certain phenomena consistently, the identification of inner incoherencies, or its inadequacy to guide action and manipulate objects effectively can lead to the revision of a theory. Sticking to this fundamental insight and leaving aside other aspects of Kuhn's theory, this evolutionary approach has been generalised and used to account for intellectual progress more generally. In this view, intellectual progress is triggered by irritations in our performative experience of reality, that is, it is brought about by our efforts to solve the problems that we encounter in coping with the world. Hence, problem solving (i.e. moving away from irritations), rather than gradually approaching "reality" (i.e. moving towards a fixed goal), is said to be the driver of intellectual progress ${ }^{11}$ (Habermas, 1999; Rorty, 2007; Roth, 2012; Sorrell, 2013).

This also applies to practical reason, concerned with the question of what we ought to do. Reflection on this question not only has to assess the efficiency of different means of achieving certain ends, but also has to take into account "the opposition of other social actors whose value orientations conflict with ours" (Habermas, 1999: 42). Be it in the short, medium or long term, this latter challenge can trigger learning processes and the decentralisation of one's own perspective in order to understand these value conflicts and respond to them in one way or another. At stake, then, is moral learning, that is, the "intelligent expansion and reciprocal interpenetration of social worlds that in a given case of conflict do not yet sufficiently overlap" (Habermas, 1999: 105). Academic discussion on moral relativism and universality is a case in point. Given

11 In comparison to other spheres of human activity, which also produce knowledge, the specificity of scientific knowledge is that it is based on the systematic generation of problems. 
that practical conflicts arise from the opposition of others, consensual agreements are often necessary to solve these problems, that is, to eliminate this opposition in the first instance, or at least make it manageable. ${ }^{12}$ Thus, what is required is that the "disputing parties learn to include one another in a world they construct together so as to be able to judge and consensually resolve controversial actions in the light of matching standards of evaluation" (Habermas, 1999: 105). Again, the expression "resolve [controversial actions]" should be understood in a broad sense, that is, as including arrangements which do not strictly speaking eliminate disagreement, such as granting rights like freedom of religion, but which make it simply manageable because they are based on a legitimate dissent (see the point on legitimate dissent above, as well as Habermas, 1999: 227-228).

This image of practical reason as a problem-solving activity is consistent with the more general account of intellectual progress as problem solving. In both cases, learning processes help us revise our cognitive structures with a view to overcoming problems that we experience performatively in our interaction with the world and with others. This does not mean that learning processes, when they occur, ${ }^{13}$ are always successful. However, although fallible, their prima facie validity stems from the fact that they have overcome the problems and shortcomings of the previously dominant cognitive structures, be it regarding practical questions or questions about the correct representation of the "objective" world, as in scientific progress.

With this account of intellectual progress in place, deliberative theory is able to respond to the challenge of ethnocentrism -and it does so by telling a story. Essentially, this story describes the evolution of moral beliefs to the present day, that is, how former self-evident and sacralised worldviews, which justified specific social and political orders, have undergone a process of de-sacralisation, contestation and complexification that mirrors to some extent the inner differentiation, pluralisation and complexification of societies (Habermas, 1981: 64 ff., 1996: 11-64, 1999: 261266). One of the consequences of this process of modernisation -so the story goes-

${ }^{12}$ Certainly, one can argue that another alternative is the physical elimination of the other, which would also put an end to opposition. There are at least two possible answers to this objection. First, sticking to the conception of intellectual and moral progress as problem solving and trying not to take for granted any aprioristic moral commitments on the part of the conflicting parties, one argument that can prioritise consensual agreement over physical confrontation is the observation that the latter usually seems to aggravate, rather than improve, social conflicts. The problem with this argument, however, is that it makes morality depend on non-moral considerations, which would undermine its autonomy. This is a problem especially for Kantian philosophers. Another alternative, which avoids this difficulty, is to argue that moral learning presupposes that people always already adopt a moral perspective, i.e. that they take as their reference point "an ideally projected social world of legitimately ordered interpersonal relationships" which they collectively have to define in each case and bring about (Habermas, 1999: 261).

${ }^{13}$ Certainly, learning processes might be blocked, take pathological turns, or simply fail to change a situation significantly (in this regard, see Eder, 1991, 1999; Miller, 2006). 
is that "more and more people [encounter] more and more others in other roles and different situations as less and less familiar counterparts: They encounter one another as strangers" (Habermas, 1999: 263) -hence, what political theorists since Rawls have called the fact of pluralism. This fact of pluralism has to be organised politically, not only within nation states, which are increasingly diverse, but also in the international arena (Apel, 2000). In such a situation, social actors can no longer rely on self-evident truths, but have to construct self-consciously their social and political orders together, but without recourse to substantive worldviews which are not shared by everybody.

It is in this context that deliberative democracy can be justified. Essentially, what it claims is that notwithstanding the fact of pluralism, all human beings share in one form or another the capacity for language use and argumentation. Thus, social actors who can no longer rely on their cultural traditions to organise their coexistence might wish to explore whether their shared practices offer them enough normative elements through which to organise their living together (Habermas, 1996: 56-64; Stahl, 2013). Famously, Apel and Habermas have reconstructed the pragmatic assumptions that no-one in an argumentation can avoid making once they enter it: the sincerity of the speakers, the absence of coercion, the non-exclusion of relevant topics and perspectives, and so on. The point is that these are not assumptions specific to 'our' (Western, European, academic, or whatever) conception of argumentation, but are constitutive of argumentation itself. In other words, if these assumptions are violated and this becomes obvious, we leave the game of argumentation and start a new one, whatever that is. At least this is the thesis put forward by Apel and Habermas, a thesis which has been very influential among deliberative democrats.

In this context, the egalitarian universalistic "bias" of deliberative democracy, which makes it appear ethnocentric, stems in the first place from the counterfactual assumptions of argumentation, not from a specific cultural or moral tradition. "Lest the discussion of disputed validity claims forfeit its cognitive purpose, participants in argumentation must subscribe to an egalitarian universalism that is structurally mandated and that at first has only a formal-pragmatic, rather than a moral, meaning" (Habermas, 1999: 106). The proposal of deliberative democrats is, then, that we can organise our political systems in such a way that they approach these pragmatic assumptions of argumentation as closely as possible -given that these assumptions are universal, a political system based on them could in principle be recognised as legitimate by everybody. So, they argue, deliberative democracy is a plausible ideal with which to solve the problem of how to organise ourselves politically in a context marked by the fact of pluralism. Certainly, the ideal of deliberative democracy does not guarantee that we will be able to solve our practical disputes, but if this is still possible at all, public deliberation is the most appropriate means of doing so, given its epistemic edge and universal character.

To summarise, this narrative describes our current political problems and contributes to justifying the prima facie validity of deliberative democracy by showing how it can help to respond to these historically specific challenges. According to the account of intellectual progress presented earlier, deliberative democracy can be seen as the result of a learning process, i.e. as a prima facie valid response to the problem of how to 
organise coexistence in a context characterised by a plurality of value orientations hence, it can be seen as an instance of practical progress. If this historic justification of deliberative democracy is accepted, the arguments for the epistemic superiority of deliberation vis-à-vis other democratic procedures regain their validity, given that the egalitarian universalistic bias of deliberative democracy derives from the pragmatic presuppositions of discourse, the application of which to the realm of politics has been recognised as the result of a collective learning process, i.e. as a case of practical progress.

Certainly, these are good but ultimately fallible reasons in support of deliberative democracy in the sense that they do not amount to a decisive, irrefutable justification of this political ideal. In any case, the exposition above illustrates a more humble point, which has, however, been overlooked by most discussions of the role of narrative and storytelling in deliberative democracy; namely, that deliberative theory itself cannot rely on argumentation devoid of narrative elements. They do not simply illustrate or make deliberative theory more colourful, but contribute to the very justification of this political ideal, that is, they are essential to articulate certain reasons in the first place. In line with the reading of the strong conception of narrative presented here, which ultimately grounds the sociocultural significance of narratives in empirical observation (rather than logical arguments or arguments of any other kind), the contention that deliberative theory also rests on narrative elements does not prove anything, but simply provides further evidence of the importance of narratives. In particular, it gives further plausibility to the claim that narratives are not only compatible with deliberation, but are even unavoidable, for without narratives some arguments could not be formulated in the first place.

\section{Conclusion and Future Research}

In this article, I have concentrated on the debate about the legitimate or illegitimate place of storytelling in deliberation. I have distinguished between a weak concept of narrative, according to which narratives are just another rhetorical device among many that can be used (or not used) to convey meaning, and a strong conception, which sees narratives as an unavoidable feature of human communication, playing a fundamental role in the shaping of the symbolic and social world in which social actors live. Whilst the weak conception of narrative - the one that has usually been discussed by deliberative theorists -seems to be compatible with the theory of deliberative democracy, the strong conception, favoured by many social theorists and "postmodern" philosophers, has been interpreted as challenging some of the tenets of the epistemic justification of deliberative democracy. If these arguments were right, integrating the concept of storytelling into deliberative theory would be akin to a Trojan horse, that is, it would undermine the justification of deliberative democracy from within, so to speak. I have argued, however, that these criticisms rest on shaky conceptual and logical grounds. Furthermore, in line with the strong conception of narrative, I have contended that a plausible justification of deliberative democracy requires the use of narrative elements -a point usually overlooked by most discussions of the relation 
between narratives and deliberation. With this, I have tried to strengthen the case that narratives are not only conceptually compatible with deliberative theory, but are also necessary to articulate certain arguments in the first place, that is, they are inevitably part and parcel of deliberation.

This argument provides an answer to the question whether storytelling should be part of public deliberation, but in so doing, it leads to further issues, both normative and empirical. From a normative perspective, for instance, it would be necessary to clarify whether the use of narratives in public deliberation should be restricted to specific cases - for example, to the telling of particular historical events or processes (however idealised), as in the example mentioned in the previous section. Furthermore, it should be elucidated whether special obligations apply to storytelling in some situations. For example, when it comes to stories about specific social groups, it might be reasonable to demand from speakers that they clarify to what extent these stories can be generalised to specific groups. Yet, these special obligations might conflict with the idea that storytelling favours inclusive deliberative practices. Empirical research, for its part, has provided some initial results concerning additional questions raised by this paper, although further evidence is needed. Some of these issues are: Are social actors more likely to use narratives when it comes to certain topics rather than others? Is storytelling likely to lead to different, possibly less confrontational, styles of deliberation (Polleta and Lee, 2006)? Are certain narrative genres better suited to public deliberation than others (Forchtner and Eder, forthcoming)? But these and further questions should be the topic of future research.

\section{References}

Abizadeh, A. (2007): "On the Philosophy/ Rhetoric Binaries: Or, Is Habermasian Discourse Motivationally Impotent?", Philosophy and Social Criticism, 33 (4), pp. 445-472.

Alexander, J.C. (2002): "On the Social Construction of Moral Universals: The 'Holocaust' from War Crime to Trauma Drama", European Journal of Social Theory, 5 (1), pp. 5-85.

Alexander, J.C. (2004): "Cultural Pragmatics: Social Performance Between Ritual and Strategy", Sociological Theory, 22 (4), pp. 527-573.

Apel, K.O. (2000): "Globalization and the Need for Universal Ethics", European Journal of Social Theory, 3 (2), pp. 137-155.

Bächtiger, A., S. Niemeyer, M. Neblo, M.R. Steenbergen and J. Steiner (2010): "Disentangling Diversity in Deliberative Democracy: Competing Theories, Their Blind Spots and Complementarities", The Journal of Political Philosophy, 18 (1), pp. 32-63.

Bailin, S. (2003): "Is Argument for Conservatives? or Where Do Sparkling New Ideas Come From?", Informal Logics, 23 (1), pp. 3-17.

Bohman, J. (2007): "Political Communication and the Epistemic Value of Diversity: Deliberation and Legitimation in Media Societies", Communication Theory, 17 (4), pp. 348-355. 
Bohman, J. and W. Rehg (2014): "Jürgen Habermas", in E.N. Zalta, ed., The Stanford Encyclopedia of Philosophy (Fall 2014 Edition). Available at: http://plato.stanford. edu/archives/fall2014/entries/habermas/ [Accessed: 09 September 2014].

Boswell, J. (2013): "Why and How Narrative Matters in Deliberative Systems", Political Studies, 61 (3), pp. 620-636.

Chambers, S. (2003): "Deliberative Democratic Theory", Annual Review of Political Science, 6, pp. 307-326.

Chambers, S. (2009): "Rhetoric and the Public Sphere: Has Deliberative Democracy Abandoned Mass Democracy?", Political Theory, 37 (3), pp. 323-350.

Dryzek, J.S. (2000): Deliberative Democracy and Beyond, Oxford, Oxford University Press.

Dryzek, J.S. (2010): "Rhetoric in Democracy: A Systemic Appreciation", Political Theory, 38 (3), pp. 319-339.

Dryzek, J. and S. Niemeyer (2006): "Reconciling Pluralism and Consensus as Political Ideals", American Journal of Political Science, 50 (3), pp. 634-649.

Eder, K. (1991): Geschichte als Lernprozeß? Zur Pathogenese politischer Modernität in Deutschland, Frankfurt am Main, Suhrkamp.

Eder, K. (1999): "Societies Learn and yet the World is Hard to Change", European Journal of Social Theory, 2 (2), pp. 195-215.

Eder, K. (2006): "Europe's Borders: The Narrative Constructions of the Boundaries of Europe", European Journal of Social Theory, 9 (2), pp. 255-271.

Eder, K. (2009): "A Theory of Collective Identity: Making Sense of the Debate on a 'European Identity"', European Journal of Social Theory, 12 (4), pp. 427-447.

Engelken-Jorge, M. (2014): "Ignorancia política y saber práctico: el valor de la opinión pública", in S. Gallego Trijueque and E. Díaz Cano (coords.), XII Premio de Ensayo Breve de la Asociación Castellano-Manchega de Sociología "Fermín Caballero", Toledo, Asociación Castellano-Manchega de Sociología, pp. 79-98.

Estlund, D.M. (2009): Democratic Authority: A Philosophical Framework, Princeton, Princeton University Press.

Finlayson, A. (2012): "Rhetoric and the Political Theory of Ideologies", Political Studies, 60 (4), pp. 751-767.

Fisher, W.E. (1984): "Narration as a Human Communication Paradigm: The Case of Public Moral Argument", Communication Monographs, 51 (1), pp. 1-22.

Fontana, B., C.J. Nederman and G. Remer, (eds.) (2004): Talking Democracy: Historical Perspectives on Rhetoric and Democracy, Pennsylvania, The Pennsylvania State University Press.

Forchtner, B. and K. Eder (forthcoming): "Europa erzählen: Strukturen Europäischer Identität", in H.-W. Platzer and G. Hentges (eds.), Europäische Identität in der Krise?, Wiesbaden, VS.

Garsten, B. (2011): "The Rhetoric Revival in Political Theory", Annual Review of Political Science, 14, pp. 159-180.

Geertz, C. (1973): "Thick Description: Toward an Interpretive Theory of Culture", in C. Geertz, The Interpretation of Cultures: Selected Essays, New York, Basic Books, pp. 3-30. 
Habermas, J. (1981): Teoría de la acción comunicativa, II. Crítica de la razón funcionalista, Madrid, Taurus, 2003.

Habermas, J. (1992): Faktizität und Geltung. Beiträge zur Diskurstheorie des Rechts und des demokratischen Rechtsstaats, Frankfurt am Main, Suhrkamp, 1994.

Habermas, J. (1996): Die Einbeziehung des Anderen. Studien zur politischen Theorie, Frankfurt am Main, Suhrkamp.

Habermas, J. (1999): Truth and Justification, Cambridge, Massachusetts, The MIT Press, 2003

Habermas, J. (2006): "Political Communication in Media Society: Does Democracy Still Enjoy an Epistemic Dimension? The Impact of Normative Theory on Empirical Research", Communication Theory, 16 (4), pp. 411-426.

Hatcher, D. (1994): "Critical Thinking, Postmodernism, and Rational Evaluation", Informal Logics, 16 (3), pp. 197-208.

Ibarra Güell, P. (2011): Democracia Relacional, Madrid, Centro de Estudios Políticos y Constitucionales.

Joas, H. (2008): "Value Generalization: Limitations and Possibilities of a Communication about Values", Zeitschrift für Wirtschafts- und Unternehmensethik, 9 (1), pp. 88-96.

Joas, H. (2011): Die Sakralität der Person: Eine neue Genealogie der Menschenrechte, Berlin, Suhrkamp.

Kock, C. (2007): "Norms of Legitimate Dissensus", Informal Logic, 27 (2), pp. 179196.

Lafont, C. (2006): "Is the Ideal of a Deliberative Democracy Coherent?", in S. Besson and J.L. Martí (eds.), Deliberative Democracy and Its Discontents, Aldershot, Ashgate, pp. 3-25.

Luhmann, N. 1984: Sistemas sociales. Lineamientos para una teoría general, Barcelona, Anthropos, 1998.

MacIntyre, A. 1984: Tras la virtud, Barcelona, Crítica, 2004.

Martí, J.L. (2006): "The Epistemic Conception of Deliberative Democracy Defended: Reasons, Rightness and Equal Political Autonomy", in S. Besson and J.L. Martí (eds.), Deliberative Democracy and Its Discontents, Aldershot, Ashgate, pp. 27-56.

Martin, J.L. (2002): "Power, Authority, and the Constraint of Belief Systems", American Journal of Sociology, 107 (4), pp. 861-904.

Miller, M. (2006): Dissens: Zur Theorie diskursiven und systemischen Lernens, Bielefeld, Transcript.

Neblo, M.A. (2007): "Family Disputes: Diversity in Defining and Measuring Deliberation", Swiss Political Science Review, 13 (4), pp. 527-557.

Niemeyer, S. (2011): "The Emancipatory Effect of Deliberation: Empirical Lessons from Mini-Publics", Politics \& Society, 39 (1), pp. 103-140.

Oberheim, E. (2013): "The Incommensurability of Scientific Theories", in E.N. Zalta, ed., Stanford Encyclopaedia of Philosophy (Spring 2013 Edition). Available at: http://plato.stanford.edu/entries/incommensurability/ [Accessed: 09 September 2014].

Parkinson, J. and J. Mansbridge, eds. (2013): Deliberative Systems: Deliberative Democracy at the Large Scale, Cambridge, Cambridge University Press. 
Polletta, F. and J. Lee (2006): "Is Telling Stories Good for Democracy? Rhetoric in Public Deliberation after 9/11", American Sociological Review, 71 (5), pp. 699-723.

Ricoeur, P. (1979): "The Human Experience of Time and Narrative", Research in Phenomenology, 9, pp. 17-34.

Ricoeur, P. (1990): Oneself as Another, Chicago, University of Chicago Press, 1992.

Rorty, R. (1989): Contigency, Irony, and Solidarity, Cambridge, Cambridge University Press.

Rorty, R. (1990a): "Feminism and Pragmatism", The Tanner Lectures on Human Values, delivered at University of Michigan, December 7, 1990. Available at: http:// tannerlectures.utah.edu/_documents/a-to-z/r/rorty92.pdf [Accessed: 09 September 2014].

Rorty, R. (1990b): "Truth and Freedom: A Reply to Thomas McCarthy", Critical Inquiry, 16 (3), pp. 633-643.

Rorty, R. (2007): "Dewey and Posner on Pragmatism and Moral Progress", The University of Chicago Law Review, 74, pp. 915-927.

Roth, A. (2012): "Ethical Progress as Problem-Resolving", The Journal of Political Philosophy, 20 (4), pp. 384-406.

Sanders, L.M. (1997): “Against deliberation”, Political Theory, 25 (3), pp. 347-376.

Somers, M.R. (1994): "The Narrative Constitution of Identity: A relational and network approach", Theory and Society, 23 (5), pp. 605-649.

Somers, M.R. (1998): “'We're No Angels': Realism, Rational Choice, and Relationality in Social Science", American Journal of Sociology, 104 (3), pp. 722-784.

Sorrell, K. (2013): "Pragmatism and moral progress: John Dewey's theory of social inquiry", Philosophy \& Social Criticism, 39 (8), pp. 809-824.

Stahl, T. (2013): "Habermas and the Project of Immanent Critique", Constellations, 20 (4), pp. 533-552.

Steiner, J. (2012): The Foundations of Deliberative Democracy: Empirical Research and Normative Implications, Cambridge, Cambridge University Press.

Swidler, A. (1986): "Culture in Action: Symbols and Strategies", American Sociological Review, 51 (2), pp. 273-286.

Tilly, C. (2002): Stories, Identities, and Political Change, Oxford, Rowman \& Littlefield Publishers.

Warren, M.E. (2007): "Institutionalizing deliberative democracy", in S. Rosenberg (ed.), Deliberation, Participation and Democracy: Can the People Govern?, London, Palgrave-Macmillan, pp. 272-288.

Wuthnow, R. (ed.) (1992): Vocabularies of Public Life: Empirical Essays in Symbolic Structure, London, Routledge.

Yack, B. (2006): "Rhetoric and Public Reasoning: An Aristotelian Understanding of Political Deliberation", Political Theory, 34 (4), pp. 417-438.

Young, I.M. (2001): "Activist challenges to deliberative democracy", Political Theory, 29 (5), pp. 670-690.

Young, I.M. (2002): "Inclusive Political Communication", in I.M. Young, Inclusion and Democracy, Oxford, Oxford University Press, pp. 52-80. 